\title{
ANALISIS NILAI TAMBAH AGROINDUSTRI PENGOLAHAN KOPI ARABIKA EKSPOR DI KABUPATEN ACEH TENGAH (STUDI KASUS PADA KSU SARA ATE)
}

\author{
Peggi Epaga $^{1}$, Akhmad Baihaqi ${ }^{1}$, Mujiburrahmad ${ }^{1}$, Elly Susanti ${ }^{1}$ \\ ${ }^{1}$ Program Studi Agribisnis, Fakultas Pertanian, Universitas Syiah Kuala
}

\begin{abstract}
Abstrak
Penelitian ini bertujuan untuk mengetahui seberapa besar agroindustri pengolahan kopi arabika ekspor pada KSU Sara Ate di Kabupaten Aceh Tengah dapat menciptakan nilai tambah untuk kopi dan untuk mengetahui apakah sudah efesien pemasaran kopi arabika ekspor pada KSU Sara Ate di Kabupaten Aceh Tengah. Penentuan lokasi penelitian ini ditentukan secara sengaja (Purposive) dengan pertimbangan karena industri pengolahan kopi ini berproduksi secara berkesinambungan dan juga merupakan salah satu industri pengolahan kopi di Aceh Tengah. Metode analisis yang digunakan pada penelitian ini adalah metode analisis nilai tambah model hayami dan metode analisis efesiensi pemasaran. Hasil analisis menunjukkan nilai tambah kopi arabika ekspor green bean grade 1 (spesialty) pada KSU Sara Ate sedang, dan green bean grade 2 (premium) rendah. Berdasarkan nilai efesiensi pemasaran green bean grade 1 dan green bean grade 2 pada KSU Sara Ate pemasaran dinilai efesien. Nilai tersebut memenuhi syarat ketentuan dimana jika EP 0-50 \% pemasaran dinilai efesien.
\end{abstract}

Kata kunci: Nilai Tambah, Efesiensi Pemasaran, Kopi Arabika Ekspor

\begin{abstract}
This study aims to find out how big arabica coffee processing export agroindustry in KSU Sara Ate in Central Aceh Regency can create added value for coffee and to know whether it has efficient marketing arabica coffee export at KSU Sara Ate in Central Aceh regency. Determination of the location of this study is determined purposively (Purposive) with consideration because the coffee processing industry is producing continuously and is also one of the coffee processing industry in Central Aceh. The method of analysis used in this research is the value added analysis method of hayami model and marketing efficiency analysis method. The analysis result shows the value of arabica coffee export of green bean grade 1 (specialty) on KSU Sara Ate being, and green bean grade 2 (premium) low. Based on the value of marketing efficiency of green bean grade 1 and green bean grade 2 on KSU Sara Ate marketing is considered efficient. The value is eligible provisions where if 0-50\% EP marketing is considered efficient.
\end{abstract}

Keywords: Value-added, Marketing Efficiency, Arabica Export Coffee

\section{Pendahuluan}

Perkembangan volume ekspor kopi Indonesia pada beberapa tahun terakhir cenderung meningkat dengan pertumbuhan ratarata sebesar $4,39 \%$ per tahun. Jika pada tahun 2010 volume ekspor kopi Indonesia sebesar 321.677 ton dengan nilai ekspor sebesar US\$ 856 juta, maka tahun 2015 volume ekspor meningkat menjadi 540.021 ton atau senilai US\$ 1.198 juta (AEKI, 2016). Kopi Gayo memliki posisi pasar Internasional yang kuat, jumlah kopi arabika yang diekspor dari Kabupaten Aceh Tengah ke mancanegara dari bulan Januari sampai bulan September 2015 mencapai 7.000 ton lebih dengan nilai 39,9 juta dolar AS atau sekitar Rp.486 miliar dalam bentuk green bean (Serambi, 2016).

Menurut Saragih (2010) dengan adanya suatu pengolahan terhadap beberapa produk akan mendapatkan produk yang bernilai lebih tinggi. Pada saat ini, pendekatan pembangunan pertanian diarahkan pada pengembangan produk, dan tidak lagi fokus pada pengembangan komoditas, perkembangan produk saat ini fokus dalam memeberikan nilai lebih melalui 
pengembangan industri yang memproses produk pertanian primer menjadi produk olahan, produk setengah jadi dan produk akhir.

pembangunan pertanian diarahkan pada pengembangan produk, dan tidak lagi fokus pada pengembangan komoditas, perkembangan produk saat ini fokus dalam memeberikan nilai lebih melalui pengembangan industri yang memproses produk pertanian primer menjadi produk olahan, produk setengah jadi dan produk akhir. Akan tetapi selama ini kopi Gayo yang diperdagangkan sebagai bahan baku berbentuk green bean (Serambi, 2016). Terlebih dengan banyaknya negara pesaing yang juga penghasil kopi. Beberapa alasan kopi Indonesia yang menjadi ekspor terbesar kopi adalah kopi hijau, karena Indonesia masih ada yang belum terpenuhi standar kualitas Internasional. Disamping itu negara yang merupakan negara produsen kopi, seperti Brazil dan Kolombia juga menimbulkan anacaman dan tantangan tersendiri untuk ekspor kopi Indonesia (AEKI, 2014).

Salah satu agroindustri di Aceh Tengah yang melakukan pengolahan kopi ekspor adalah Oro Coffee Gayo yang berdiri pada tahun 2009 dan baru mendapatkan izin untuk beroprasi pada tahun 2011. Kini bermunculan pengolahan kopi yang bergerak di bidang ekspor kopi dan merupakan agroindustri yang tergolong baru dan sudah memiliki pangsa pasar yang luas seperti yang dilakukan oleh KSU Sara Ate yang berdiri pada tahun 2013 Kedua agroindustri pengolahan kopi diatas memiliki produk yang relatif sama green bean spesailty atau green bean grade 1 dan green bean grade 2 (premium). Produsen kopi perlu menggunakan kemampuan yang dimilikinya untuk menghasilkan produk yang memiliki nilai tambah, harga tinggi yang dapat bersaing dan sesuai dengan kenginginan buyer pembeli. Dengan adanya pengolahan kopi diharapkan dapat menciptakan nilai tambah kopi menjadi lebih baik dan diharapkan dapat mampu bersaing dengan negara produsen kopi lainya.

Tujuan dari penelitian ini adalah 1) Untuk menganalisis seberapa besar agroindustri pengolahan kopi arabika ekspor pada KSU Sara Ate di Kabupaten Aceh Tengah dapat menciptakan nilai tambah untuk kopi. 2) Untuk mengetahui apakah sudah efesien pemasaran kopi arabika ekspor pada KSU Sara Ate di Kabupaten Aceh Tengah.

\section{Metode Penelitian}

Penelitian ini dilakukan di KSU Sara Ate di Jl. Takengon - Angkup, Uning, Pegasing, Kabupaten Aceh Tengah. Lokasi penelitian ini ditentukan secara Purpossive Sampling (sengaja) dengan pertimbangan karena industri pengolahan kopi ini berproduksi secara berkesinambungan dan juga merupakan salah satu industri pengolahan kopi di Aceh Tengah. Pelaksanaan penelitian ini dimulai pada awal bulan Oktober 2017 sampai dengan 1 November 2017. Objek dalam penelitian ini adalah agroindustri pengolahan kopi ekspor kopi KSU Sara Ate di Kabupaten Aceh Tengah. Ruang lingkup penelitian ini terbatas pada analisis nilai tambah dan efesiensi pemasaran kopi arabika ekspor pada KSU Sara Ate di Kabupaten Aceh Tengah.

Metode yang digunakan dalam penelitian ini adalah metode studi kasus (case study), karena metode ini menekankan kedalaman analisis pada kasus tertentu yang lebih spesifik. Metode analisis yang digunakan dalam penelitian ini adalah Metode Hayami, dan metode analisis efesiensi pemasaran.

\section{Pengukuran Nilai Tambah Menggunakan Metode Hayami}

Analisis nilai tambah metode Hayami merupakan metode yang memperkirakan perubahan nilai bahan baku setelah mendapatkan perlakuan. Rumus yang digunakan dapat diformulasikan sebagai berikut: (Hayami, et al 1987). 
Tabel 1

Analisis Input, Output, dan Harga

Analisis Nilai Tambah Model Hayami

Satu Kali Proses Produksi Kopi Pada Oro

Coffe Gayo dan KSU Sara Ate di

Kabupaten Aceh Tengah.

\begin{tabular}{|c|c|c|c|}
\hline No. & Variabel & $\begin{array}{l}\text { Satua } \\
\text { n }\end{array}$ & Notasi \\
\hline I & $\begin{array}{l}\text { Input, } \\
\text { Output, } \\
\text { Harga } \\
\end{array}$ & & \\
\hline 1. & Input $*$ & $\begin{array}{l}\mathrm{Kg} / \mathrm{pe} \\
\text { riode }\end{array}$ & $\begin{array}{l}\text { Bahan baku yang } \\
\text { digunakan untuk } \\
\text { memproduksi } \\
\text { kopi dalam satu } \\
\text { kali proses } \\
\text { produksi }\end{array}$ \\
\hline 2. & Output & $\begin{array}{l}\mathrm{Kg} / \mathrm{pe} \\
\text { riode }\end{array}$ & $\begin{array}{l}\text { Total produksi } \\
\text { kopi arabika yang } \\
\text { dihasilkan oleh } \\
\text { agroindustri kopi } \\
\text { arabika } \\
\text { Bahan baku yang } \\
\text { digunakan untuk } \\
\text { memproduksi } \\
\text { kopi dalam satu } \\
\text { kali proses } \\
\text { produksi }\end{array}$ \\
\hline 3. & $\begin{array}{l}\text { Tenaga } \\
\text { Kerja }\end{array}$ & $\begin{array}{l}\mathrm{HOK} / \\
\text { perio } \\
\text { de }\end{array}$ & $\begin{array}{l}\text { Hari Orang Kerja } \\
\text { dalam satu } \\
\text { periode analisis }\end{array}$ \\
\hline 4. & $\begin{array}{l}\text { Faktor } \\
\text { Konversi }\end{array}$ & $\begin{array}{l}\mathrm{Kg} / \mathrm{pe} \\
\text { riode }\end{array}$ & $\begin{array}{l}\text { Faktor Konversi = } \\
\text { Output } / \text { Input }\end{array}$ \\
\hline 5. & $\begin{array}{l}\text { Koefisien } \\
\text { Tenaga } \\
\text { Kerja }\end{array}$ & $\begin{array}{l}\mathrm{HOK} / \\
\mathrm{kg}\end{array}$ & $\begin{array}{l}\text { Koefisien Tenaga } \\
\text { kerja = Tenaga } \\
\text { Kerja / Input }\end{array}$ \\
\hline 6. & $\begin{array}{l}\text { Harga } \\
\text { Output }\end{array}$ & $\mathrm{Rp} / \mathrm{kg}$ & $\begin{array}{lr}\text { Harga produk } & \text { prong berlaku pada } \\
\text { yang } & \text { satu periode } \\
\text { analisis } & \end{array}$ \\
\hline 7. & $\begin{array}{l}\text { Upah Rata- } \\
\text { Rata } \\
\text { Tenaga } \\
\text { Kerja }\end{array}$ & $\begin{array}{l}\mathrm{Rp} / \mathrm{pe} \\
\text { riode }\end{array}$ & $\begin{array}{l}\text { Jumlah upah rata- } \\
\text { rata yang diterima } \\
\text { oleh pekerja } \\
\text { dalam setiap satu } \\
\text { periode produksi } \\
\text { yang dihitung } \\
\text { berdasarkan per } \\
\text { HOK (Hari Orang } \\
\text { Kerja) }\end{array}$ \\
\hline
\end{tabular}

Sumber : (Hayami, et al,1987)

Keterangan : * satu kali proses produksi

** Input lain = kemasan (karung), benang, jarum, penggerak mesin pengolahan

*** Keuntungan dinilai atas biaya Operasi (bahan baku, input lain, dan tenaga kerja)
Tabel 2

Analisis Pendapatan dan Keuntungan Analisis Nilai Tambah Model Hayami dalam Satu Kali Proses Produksi Pada Oro Coffee Gayo dan KSU Sara Ate di Kabupaten Aceh Tengah

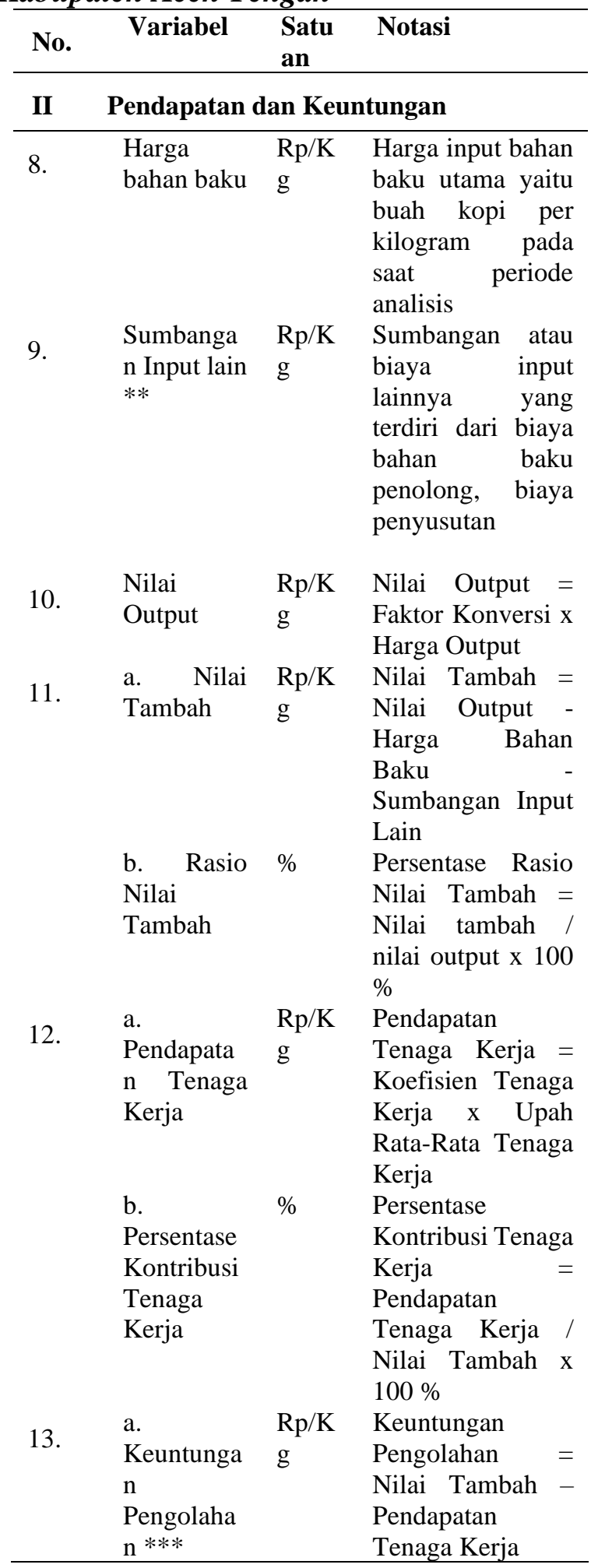




\begin{tabular}{|c|c|c|c|}
\hline & $\begin{array}{l}\text { b. Tingka } \\
\text { keuntunga } \\
\mathrm{n}\end{array}$ & $\%$ & $\begin{array}{l}\text { Tingkat } \\
\text { Keuntungan } \\
\text { Keuntungan } \\
\text { Pengolahan / Nilai } \\
\text { Output x } 100 \%\end{array}$ \\
\hline \multicolumn{4}{|c|}{$\begin{array}{r}\text { Sumber : (Hayami, et al,1987) } \\
\text { Keterangan : }{ }^{*} \text { satu kali proses } \\
* * \text { Input lain }=\mathrm{ke} \\
\text { benang, jarum } \\
\text { pengolahan } \\
* * * \text { Keuntungan } \\
\text { operasi (bah } \\
\text { dan tenaga ke }\end{array}$} \\
\hline \multicolumn{4}{|c|}{$\begin{array}{c}\text { Tabel } 3 \\
\text { Analisis Balas Jasa Faktor Produksi } \\
\text { Analisis Nilai Tambah Model Hayami } \\
\text { dalam Satu Kali Proses Produksi Pada } \\
\text { Oro Coffee Gayo dan KSU Sara Ate di } \\
\text { Kabupaten Aceh Tengah }\end{array}$} \\
\hline No. & Variabel & $\begin{array}{l}\text { Satu } \\
\text { an }\end{array}$ & Notasi \\
\hline III & Balas Jasa F & ktor $\mathbf{P}$ & oduksi \\
\hline 14. & $\begin{array}{l}\text { Margin } \\
\text { Keuntunga } \\
\mathrm{n} \\
\text { a. } \\
\text { Pendapata } \\
\text { n Tenaga } \\
\text { Kerja }\end{array}$ & $\begin{array}{l}\mathrm{Rp} / \\
\mathrm{Kg} \\
(\%)\end{array}$ & $\begin{array}{l}\text { Margin keuntungan } \\
=\text { Nilai Output - } \\
\text { Harga Bahan Baku } \\
\text { Persentase } \\
\text { Pendapatan Tenaga } \\
\text { kerja= Pendapatan } \\
\text { Tenaga Kerja / } \\
\text { Margin } \\
\text { Keuntungan x } 100 \\
\% \\
\text { Persentase } \\
\text { Sumbangan Input } \\
\text { lain = Sumbangan } \\
\text { Input Lain / Margin } \\
\text { Keuntungan x } 100 \\
\% \\
\text { Persentase } \\
\text { Keuntungan } \\
=\text { Keuntungan } \\
\text { Pengolahan } \\
\text { Margin } \\
\text { Keuntungan x } 100 \\
\text { \% }\end{array}$ \\
\hline
\end{tabular}

Sumber : (Hayami, et al,1987)

Keterangan :* satu kali proses produksi

** Input lain = kemasan (karung), benang, jarum, penggerak mesin pengolahan

*** Keuntungan dinilai atas biaya operasi (bahan baku, input lain, dan tenaga kerja)
Ada tiga indikator rasio nilai tambah Hubeis (1997) yaitu :

a. Jika besarnya rasio nilai tambah $<15 \%$, maka nilai tambahnya rendah.

b. Jika besarnya rasio nilai tambah $15 \%$ $40 \%$, maka nilai tambahnya sedang.

c. Jika besarnya rasio nilai tambah $>40 \%$, maka nilai tambahnya tinggi.

\section{Pengukuran Efesiensi Pemasaran}

Untuk mengetahui pemasaran apakah sudah efesien. Pengujian ini dilakukan dengan menggunakan konsep efisiensi pemasaran, dimana efisiensi pemasaran menurut Soekartawi (1989) merupakan perbandingan antara total biaya pemasaran dengan total nilai produk yang dipasarkan. dengan rumus sebagai berikut:

$\mathrm{EP}=\mathrm{TB} / \mathrm{TNP} \times 100 \%$

Keterangan : $\mathrm{EP}=$ efisiensi pemasaran ( persen)

(rupiah)

$\mathrm{TB}=$ total biaya pemasaran

$\mathrm{TNP}=$ total nilai produk (rupiah)

Kriteria pengambilan keputusan :

- EP sebesar 0-50 \% maka pemasaran dikatakan efesien.

- EP lebih besar dari $50 \%$ maka pemasaran tidak efesien.

Hasil Penelitian dan Pembahasan

Analisis Input, Output Dan Harga Nilai Tambah Menggunakan Metode Hayami Green Bean Grade 1

Perhitungan analisis nilai tambah pada green bean grade 1 dilihat dari input, output dan harga dapat dilihat pada Tabel 4 berikut ini: 
Tabel 4

Input, Output, dan Harga Analisis Nilai Tambah Model Hayami Green Bean Grade 1 (spesialty) Pada Oro Coffee Gayo dan KSU Sara Ate di Kabupaten Aceh Tengah

\begin{tabular}{llll}
\hline No & Variabel Satuan & $\begin{array}{l}\text { KSU Sara } \\
\text { Ate }\end{array}$ \\
\hline
\end{tabular}

I Input, Output, Harga

\begin{tabular}{lllc} 
1. & $\begin{array}{l}\text { Input } \\
\text { green bean } \\
\text { asalan }\end{array}$ & $\mathrm{Kg} /$ peri & 132.000 \\
ode & & \\
2. $\begin{array}{l}\text { Output } \\
\text { green bean } \\
\text { grade } 1\end{array}$ & $\mathrm{Kg}$ ode & 104.000 \\
3. & $\begin{array}{l}\text { Tenaga } \\
\text { kerja }\end{array}$ & $\begin{array}{l}\mathrm{HOK} / \mathrm{p} \\
\text { eriode }\end{array}$ & 30 \\
4. & $\begin{array}{l}\text { Faktor } \\
\text { konversi }\end{array}$ & $\begin{array}{l}\mathrm{Kg} / \mathrm{peri} \\
\text { ode }\end{array}$ & 0,79 \\
5. & $\begin{array}{l}\text { Koefisien } \\
\text { tenaga } \\
\text { kerja }\end{array}$ & $\mathrm{HOK} / \mathrm{k}$ & 0,000227 \\
$\mathrm{~g}$ & $\begin{array}{l}\text { Harga } \\
\text { Output }\end{array}$ & $\mathrm{Rp} / \mathrm{Kg}$ & 94.000 \\
6. & $\begin{array}{l}\text { Upah rata- } \\
\text { rata tenaga } \\
\text { kerja }\end{array}$ & $\begin{array}{l}\mathrm{Rp} \\
\text { /period } \\
\mathrm{e}\end{array}$ & 2.640 .000 \\
\hline
\end{tabular}

Sumber : Data Primer, (diolah) Tahun 2017

Berdasarkan Tabel 4 di atas dapat dilihat, volume pembelian bahan baku bulan agustus hingga september 2017 sebanyak 132.000 $\mathrm{Kg}$. Volume bahan baku perusahaan ini juga sangat tergantung pada kondisi pasar saat itu dengan beberapa faktor penentu, antara lain : (a) ketersediaan produksi pada masingmasing kolektor, (b) kuota kontrak yang telah ditanda tangani, (c) keamanan stock, dan (d) faktor perubahan harga yang diperkirakan. Terdapat perbedaan output yang dikeluarkan dari jumlah bahan baku yang digunakan pada agroindustri, dikarenakan jika semakin banyak kualitas

kopi bahan baku yang memiliki kriteria ekspor untuk green bean grade 1 (spesialty) maka lebih besar lah output yang dihasilkan. Tenaga kerja yang digunakan dalam pengolahan green bean grade 1 sebanya 30 orang. Faktor konversi pada KSU Sara Ate 0,79 yang artinya setiap pengolahan $1 \mathrm{~kg}$ green bean asalan akan menghasilkan 0,79 kg green bean spesialty (grade 1). Pada KSU Sara Ate koefesien tenaga kerjanya adalah 0,000202 HOK per kg bahan baku. Begitu juga dengan harga output tergantung pada kesepakatan nilai kontrak dengan buyer pemesanan. Pada penelitian ini upah kerja diasumsikan sesuai dengan rata-rata yang diterima oleh pekerja lepas pensortir kopi Rp 600 ,- per $\mathrm{kg}$, setiap satu periode produksi yang dihitung berdasarkan per hari orang kerja, dengan total jumlah input bahan baku yang diolah menjadi green bean grade 1 dalam sekali periode produksi.

\section{Analisis Nilai Tambah Pendapatan dan Keuntungan Green Bean Grade 1}

Besarnya pendapatan dan keuntungan analisis model hayami pada KSU Sara Ate dapat dilihat pada Tabel 5 berikut ini:

Tabel 5

Pendapatan dan Keuntungan Analisis Nilai Tambah Model Hayami Green Bean Grade 1 (Spesialty) Pada KSU Sara Ate di Kabupaten Aceh Tengah

\begin{tabular}{|c|c|}
\hline No. & Variabel \\
\hline
\end{tabular}

II Pendapatan dan Keuntungan

$\begin{array}{lllc}\text { 8. } & \begin{array}{l}\text { Harga input } \\ \text { bahan baku }\end{array} & \mathrm{Rp} / \mathrm{Kg} & 53.000 \\ \text { 9. } & \begin{array}{l}\text { Sumbangan } \\ \text { input lain }\end{array} & \mathrm{Rp} / \mathrm{Kg} & 760 \\ 10 . & \text { Nilai Output } & \mathrm{Rp} / \mathrm{Kg} & 74.260 \\ 11 . & \begin{array}{l}\text { a.Nilai } \\ \text { tambah }\end{array} & \mathrm{Rp} / \mathrm{Kg} & 20.500 \\ & & \\ \begin{array}{l}\text { b. Rasio } \\ \text { nilai tambah }\end{array} & \% & 27,61\end{array}$


12. a.

$$
\mathrm{Rp} / \mathrm{Kg}
$$

600

Pendapatan

tenaga kerja

b.

$\%$

Persentase

kontribusi

tenaga kerja

13. a.

$\mathrm{Rp} / \mathrm{Kg}$

19.900

Keuntungan

Pengolahan

b.Tingkat

Keuntungan

Sumber : Data Primer (diolah) Tahun 2017.

Berdasarkan Tabel 5 diatas, harga input bahan baku tergantung pada kualitas green bean asalan yang diperoleh dari petani binaan dan juga kesepakatan pembelian green bean asalan diantara kedua belah pihak petani dan agroindustri. Perhitunggan sumbangan input lain ini didasarkan pada besar biaya dan kapasitas kerja. Nilai output menggambarkan kemampuan mengelola proses pengolahan produk kopi. Semakin baik persiapan bahan baku dikelola semakin baik pula kulitas output. Nilai tambah menunjukkan bahwa adanya nilai output dikurang nilai input harga bahan baku dikurang nilai sumbangan input lain. Rasio nilai tambah agroindustri besarnya 15-40\% yang berarti nilai tambahnya sedang. Pendapatan tenaga kerja ini ialah pendapatan yang diperoleh tenaga kerja pengolahan yaitu tenaga kerja sortir rupiah per $\mathrm{kg}$. kontribusi tenaga kerja 2,93 persen pada KSU Sara Ate. Hasil penelitian menunjukkan bahwa agroindustri KSU Sara Ate menyumbangkan keuntungan sebesar Rp 19.900 per kg.

\section{Analisis Balas Jasa Faktor Produksi Nilai Tambah Green Bean Grade 1}

Perhitungan analisis nilai tambah juga melihat balas jasa faktor produksi yang terdiri dari pendapatan tenaga kerja, sumbangan input lain, dan keuntungan pengolahan dapat dilihat pada Tabel 6 berikut ini:

Tabel 6

Balas Jasa Untuk Faktor Produksi Analisis Nilai Tambah Model Hayami Green Bean Grade 1 (Spesialty) Pada KSU Sara Ate di Kabupaten Aceh Tengah

\begin{tabular}{|c|c|c|c|}
\hline No. & Variabel & Satuan & $\begin{array}{l}\text { KSU Sara } \\
\text { Ate }\end{array}$ \\
\hline III & \multicolumn{3}{|c|}{ Balas Jasa Faktor Produksi } \\
\hline \multirow[t]{4}{*}{14} & $\begin{array}{c}\text { Marjin } \\
\text { Keuntungan }\end{array}$ & $\mathrm{Rp} / \mathrm{Kg}$ & 21.260 \\
\hline & $\begin{array}{c}\text { a. } \\
\text { Pendapatan } \\
\text { tenaga kerja }\end{array}$ & $\%$ & 2,82 \\
\hline & $\begin{array}{c}\text { b. } \\
\text { Sumbangan } \\
\text { input lain }\end{array}$ & $\%$ & 3,57 \\
\hline & $\begin{array}{c}\text { c. } \\
\text { Keuntungan }\end{array}$ & $\%$ & 93,60 \\
\hline
\end{tabular}

Sumber : Data Primer (diolah) Tahun 2017.

Berdasarkan dari Tabel 6 diatas, besarnya balas jasa untuk faktor produksi analisis nilai tambah model Hayami green bean grade 1 diperoleh dari perbandingan sumbangan faktor produksi dengan nilai output-harga bahan baku. Hasil penelitian menunjukkan nilai balas jasa yang berpusat pada keuntungan produk green bean grade 1 (spesialty) pada Oro Coffee Gayo yang menyumbangkan balas jasa terhadap keuntungan sebesar Rp 21.260 per kg.

\section{Analisis Input, Output, dan Harga Nilai Tambah Pada Sistem Green Bean Asalan menjadi Green Bean Grade 2}

Perhitungan analisis nilai tambah pada green bean grade 2 dilihat dari input, output dan harga dapat dilihat pada Tabel 7 berikut ini: Tabel 7

Input, Output, dan Harga Analisis Nilai Tambah Model Hayami Green Bean Grade 2 (premium) Pada KSU Sara Ate di Kabupaten Aceh Tengah 
Tabel 7

Harga Input dan Output Hayami Green Bean Grade 2 (premium) Pada KSU Sara Ate di Kabupaten Aceh Tengah

\begin{tabular}{|c|c|c|c|}
\hline No. & Variabel & Satuan & KSU Sara Ate \\
\hline I & $\begin{array}{l}\text { Input, } \\
\text { Output, } \\
\text { Harga }\end{array}$ & & \\
\hline 1. & $\begin{array}{l}\text { Input } \\
\text { Green bean } \\
\text { asalan }\end{array}$ & $\begin{array}{l}\mathrm{Kg} / \mathrm{pe} \\
\text { riode }\end{array}$ & 55.500 \\
\hline 2. & $\begin{array}{l}\text { Output } \\
\text { Green } \\
\text { bean grade } \\
2\end{array}$ & $\begin{array}{l}\mathrm{Kg} / \mathrm{pe} \\
\text { riode }\end{array}$ & 48.000 \\
\hline 3. & $\begin{array}{l}\text { Input } \\
\text { tenaga } \\
\text { kerja }\end{array}$ & $\begin{array}{l}\mathrm{HOK} / \\
\text { period } \\
\mathrm{e}\end{array}$ & 23 \\
\hline 4. & $\begin{array}{l}\text { Faktor } \\
\text { konversi }\end{array}$ & $\begin{array}{l}\mathrm{Kg} / \mathrm{pe} \\
\text { riode }\end{array}$ & 0.86 \\
\hline 5. & $\begin{array}{l}\text { Koefisien } \\
\text { tenaga } \\
\text { kerja }\end{array}$ & $\begin{array}{l}\mathrm{HOK} / \\
\mathrm{Kg}\end{array}$ & 0,000414 \\
\hline 6. & $\begin{array}{l}\text { Harga } \\
\text { Output }\end{array}$ & $\begin{array}{l}\mathrm{Rp} \\
/ \mathrm{Kg}\end{array}$ & 70.000 \\
\hline 7. & $\begin{array}{l}\text { Upah rata- } \\
\text { rata tenaga } \\
\text { kerja }\end{array}$ & $\begin{array}{l}\text { Rp } \\
\text { /perio } \\
\text { de }\end{array}$ & 1.447 .826 \\
\hline
\end{tabular}

Sumber : Data Primer (diolah) Tahun 2017.

Berdasarkan Tabel $7 \mathrm{di}$ atas dapat dilihat, volume pembelian bahan baku pada agroindustri ini juga sangat tergantung pada kondisi pasar saat itu dengan beberapa faktor penentu, antara lain : (a) ketersediaan produksi pada masing-masing kolektor, (b) kuota kontrak yang telah ditanda tangani, (c) keamanan stock, dan (d) faktor perubahan harga yang diperkirakan. Terdapat perbedaan output yang dikeluarkan dengan jumlah bahan baku yang digunakan, hal ini terjadi jika semakin banyak kualitas kopi bahan baku yang memiliki kriteria ekspor untuk green bean grade 2 (premium) maka lebih besar lah output yang dihasilkan. Faktor konversi pada KSU Sara Ate 0,86 yang artinya setiap pengolahan $1 \mathrm{~kg}$ green bean asalan akan menghasilkan $0,86 \mathrm{~kg}$ green bean premium (grade 2). Pada Oro Coffee Gayo koefesien tenaga kerja green bean grade 2 adalah 0,000414 HOK per $\mathrm{kg}$ bahan baku. Begitu juga dengan variasi harga output untuk jenis green bean grade 1 dan green bean grade 2 berbeda, perbedaan ini juga tergantung pada kesepakatan nilai kontrak dengan buyer pemesanan. Pada penelitian ini upah kerja diasumsikan sesuai dengan rata-rata yang diterima oleh pekerja lepas pensortir kopi Rp.600,- per kg, setiap satu periode produksi yang dihitung berdasarkan per hari orang kerja, dengan total jumlah input bahan baku yang diolah dalam sekali periode produksi.

Analisis Nilai Tambah Pendapatan dan Keuntungan Green Bean Grade 2

Besarnya pendapatan dan keuntungan analisis model hayami pada KSU Sara Ate dapat dilihat pada Tabel 8 berikut ini:

\section{Tabel 8}

Pendapatan dan Keuntungan Analisis Nilai Tambah Model Hayami Green Bean Grade 2 (premium) Pada KSU Sara Ate di Kabupaten Aceh Tengah

\begin{tabular}{lll} 
No. Variabel Satuan & $\begin{array}{l}\text { KSU } \\
\text { Sara Ate }\end{array}$ \\
\hline
\end{tabular}

II Pendapatan dan Keuntungan

8. Harga input $\mathrm{Rp} / \mathrm{Kg} \quad 53.000$ bahan baku

9. Sumbangan $\mathrm{Rp} / \mathrm{Kg} \quad 566$ input lain

10. Nilai Output $\mathrm{Rp} / \mathrm{Kg} \quad 60.200$

11. a. Nilai $\mathrm{Rp} / \mathrm{Kg} \quad 6.634$ tambah

b. Rasio nilai \% $\quad 11,02$ tambah

12. a. $\quad \mathrm{Rp} / \mathrm{Kg} \quad 600$

Pendapatan tenaga kerja

b. Persentase \% $\quad 9,04$ kontibusi tenaga kerja 
13. a.

$$
\mathrm{Rp} / \mathrm{Kg} \quad 6.034
$$

Keuntungan

Pengolahan

b. Tingkat \% 10,02

Keuntungan

Sumber : Data Primer (diolah) Tahun 2017.

Berdasarkan Tabel 8 diatas, harga input bahan baku tergantung pada kualitas green bean asalan yang diperoleh dari petani binaan dan juga kesepakatan pembelian green bean asalan diantara kedua belah pihak petani dan agroindustri. Perhitunggan sumbangan input lain ini didasarkan pada besar biaya dan kapasitas kerja. Nilai output menggambarkan kemampuan mengelola proses pengolahan produk kopi. Semakin baik persiapan bahan baku dikelola semakin baik pula kulitas output. Nilai tambah menunjukkan bahwa adanya nilai output dikurang nilai input harga bahan baku dikurang nilai sumbangan input lain. Rasio nilai tambah green bean grade 2 agroindustri KSU Sara Ate besarnya $>15 \%$ yang berarti nilai tambahnya rendah. Pendapatan tenaga kerja ini ialah pendapatan yang diperoleh tenaga kerja pengolahan yaitu tenaga kerja sortir rupiah per $\mathrm{kg}$. Kontribusi tenaga kerja 9,04 persen pada KSU Sara Ate. Hasil penelitian menunjukkan bahwa agroindustri KSU Sara Ate green bean grade 2 menyumbangkan keuntungan sebesar Rp 6. 034 per kg.

\section{Analisis Balas Jasa Faktor Produksi Nilai Tambah Green Bean Grade 2}

Perhitungan analisis nilai tambah juga melihat balas jasa faktor produksi yang terdiri dari pendapatan tenaga kerja, sumbangan input lain, dan keuntungan pengolahan dapat dilihat pada Tabel 9 berikut ini:
Tabel 9

Balas Jasa Untuk Faktor Produksi Analisis Nilai Tambah Pada Green Bean Grade 2 (premium) pada KSU Sara Ate di Kabupaten Aceh Tengah

\begin{tabular}{|c|c|c|c|}
\hline No. & Variabel & Satuan & $\begin{array}{l}\text { KSU Sara } \\
\text { Ate }\end{array}$ \\
\hline III & \multicolumn{3}{|c|}{ Balas Jasa Faktor Produksi } \\
\hline \multirow[t]{4}{*}{14.} & $\begin{array}{l}\text { Marjin } \\
\text { Keuntungan }\end{array}$ & $\mathrm{Rp} / \mathrm{Kg}$ & 7.200 \\
\hline & $\begin{array}{l}\text { a. } \\
\text { Pendapatan } \\
\text { tenaga kerja }\end{array}$ & $\%$ & 8,33 \\
\hline & $\begin{array}{l}\text { b. } \\
\text { Sumbangan } \\
\text { input lain }\end{array}$ & $\%$ & 7,86 \\
\hline & $\begin{array}{l}\text { c. } \\
\text { Keuntungan }\end{array}$ & $\%$ & 83,81 \\
\hline
\end{tabular}

Sumber : Data Primer, (diolah) Tahun 2017

Berdasarkan dari Tabel 9 diatas, besarnya balas jasa untuk faktor produksi analisis nilai tambah model Hayami green bean grade 2 diperoleh dari perbandingan sumbangan faktor produksi dengan nilai output-harga bahan baku. Hasil penelitian menunjukkan nilai balas jasa yang berpusat pada keuntungan produk green bean grade 2 (premium) pada KSU Sara Ate yang menyumbangkan balas jasa terhadap keuntungan sebesar Rp 7.200 per kg. hal ini sejalan dengan penelitian Mujiburrahmad (2011) Proses pengolahan kopi mulai dari gabah sampai menjadi bubuk kopi mengalami berbagai tranformasi bentuk, setiap transformasi bentuk ini menghasilkan nilai tambah baik pada tahap Koperasi, Kolektor dan pada petani kopi. Bentuk transformasi dan nilai tambah ekonomi yang terbentuk pada masing-masing tahapan akan berbeda.

\section{Perbandingan Rasio Nilai Tambah}

Rasio nilai tambah ini menunjukkan persentase nilai tambah dari nilai produk, 
artinya jika rasio nilai tambah $<15 \%$ maka nilai tambah tergolong rendah, $15-40 \%$ nilai tambahnya sedang, sedangkan jika rasio nilai tambah > $40 \%$, maka nilai tambah tergolong tinggi. Besarnya rasio nilai tambah pada KSU Sara Ate dapat dilihat pada Tabel 10 berikut ini:

Tabel 10

Rasio Nilai Tambah Agroindustri

Pengolahan Kopi Ekspor di Kabupaten Aceh Tengah

\begin{tabular}{ll}
\hline $\begin{array}{l}\text { Produksi Kopi } \\
\text { Arabika Ekspor }\end{array}$ & \begin{tabular}{l} 
Rasio Nilai Tambah \\
\cline { 2 - 2 }
\end{tabular} \\
\cline { 2 - 2 } KSU Sara Ate \\
\hline $\begin{array}{l}\text { Green bean grade } \\
\text { (Spesialty) }\end{array}$ \\
$\begin{array}{l}\text { Green bean grade } \\
2 \text { (premium) }\end{array}$ \\
\hline
\end{tabular}

Sumber : Data Primer (diolah) Tahun 2017.

Berdasarkan Tabel 10 diatas, bahwa rasio nilai tambah ekspor kopi arabika green bean grade 1 sedang dan green bean grade 2 rendah. Sesuai dengan persentase rasio nilai tambah menurut Hubeis (1997) bahwa jika rasio nilai tambah $15-40 \%$ maka nilai tambahnya sedang dan jika rasio nilai tambah $<15 \%$ maka nilai tambah tergolong rendah.

\section{Analisis Efesiensi Pemasaran}

Kegiatan pemasaran merupakan salah satu faktor penting dalam pertanian. Jika kegiatan pemasaran berjalan dengan baik, maka pihak yang terlibat akan diuntungkan. Efesiensi pemasaran merupakan suatu indikator yang digunakan untuk mengetahui kinerja pemasaran suatu produk. Maka dapat dihitung tingkat efisiensinya dengan cara membandingkan total biaya pemasaran dengan total nilai produksi kopi arabika ekspor pada KSU Sara Ate Kabupaten Aceh
Tengah. Jika nilai EP 0-50 \% maka sistem pemasaran kopi dikatakan efisien dan jika nilai EP lebih besar dari $50 \%$ maka sistem pemasaran kopi arabika ekspor tidak efisien. Adapun besarnya nilai efesiensi pemasaran pada KSU Sara Ate dapat dilihat pada Tabel 11 berikut ini:

Tabel 11

Nilai Efisiensi Pemasaran Kopi Ekspor di Kabupaten Aceh Tengah

\begin{tabular}{ll}
\hline $\begin{array}{l}\text { Produksi Kopi } \\
\text { Arabika Ekspor }\end{array}$ & $\begin{array}{l}\text { Efesiensi } \\
\text { Pemasaran (\%) }\end{array}$ \\
\cline { 2 - 2 } & KSU Sara Ate \\
\hline Green bean grade 1 & $4,26 \%$ \\
(spesialty) & $5,71 \%$ \\
Green bean grade 2 \\
(premium)
\end{tabular}

Sumber : Data Primer (diolah) Tahun 2017.

Berdasarkan dilihat dari Tabel 11 diatas, bahwa pemasaran ekspor kopi arabika KSU Sara Ate sudah efesien. Nilai tersebut memenuhi syarat ketentuan dimana jika EP 0-50 \% maka pemasaran dinilai efesien.

\section{Simpulan dan Saran}

Adapun tingkat Analisis nilai tambah kopi ekspor arabika green bean grade 1 (spesialty) pada KSU Sara Ate nilai tambahnya sedang, dan nilai tambah green bean grade 2 (premium) KSU Sara Ate rendah.

Pemasaran pada agroindustri pengolahan kopi ekspor green bean grade 1 (spesialty) pada KSU Sara Ate efesien, dan pemasaran green bean grade 2 juga efesien. Nilai tersebut memenuhi syarat ketentuan dimana jika EP 0-50 \% maka pemasaran dinilai efesien.

Untuk mendapatkan nilai tambah yang baik diharapkan agroindustri dapat menjaga 
kualitas mutu kopi yang diharapkan oleh buyer pemesanan kopi. Kepada masingmasing agroindustri diharapkan dapat memberikan binaan lebih baik lagi kepada

\section{Daftar Pustaka}

Dwi, Rinawati. 2017. Pengakuan dan Pengukuran Pendapatan Menurut PSAK No.23 Pada Perusahaan Biro Jasa Perjalanan. Jurnal Ilmu dan Riset Akutansi. Vol 6 (1) : 152.

Fahmi, Mirza. 2013. Analisis Strategi Pemasaran Kopi Arabika 'BergendaalKoffie'Di Kabupaten Bener Meriah. Jurnal Agrisep Vol (14) (1):28-35.

Fandy, Tjiptono. 2000. Faktor-Faktor Kepuasan Pelanggan Pelanggan dan Loyalitas Pelanggan: Studi Kasus pada CV. Sarana Media Advertising Surabaya. Jurnal Manajemen dan Kewirausahaan. 2(2): 106-108.

Fitria, Ikramatul. 2016. Komparasi Efisiensi Pemasaran Sayur-sayuran di Daerah Tinggi dan Dataran Rendah. Jurnal Agrisep Vol (2) (1):77-88.

Grace, Masengi. 2014. Analisis Keuntungan Rumah Makan ElSahadai di Kawasan Kuliner

"Wakeke Manado". Jurnal Kementerian Pendidikan dan Kebudayaan. 1 (487-918).

Hayami Y, Kawagoe T, Morooka Y, Siregar M. 1987. Agricultural Marketing and Processing in Upland Java. A Perspective from a petani binaan sehingga dapat menghasilkan biji kopi yang seragam dengan kualitas terbaik.

Sunda Village. The CPGRT Centre, Bogor.

Hubeis M. 1997. Menuju Industri kecil Profesional di Era Globalisasi Melalui Pemberdayaan Manajemen Industri. IPB Press, Bogor.

Kementerian Perindustrian. 2016. Laporan Perkembangan Eksport Komoditi Kopi.

http://agro.kemenperin.go.id/catego ry/7-Industri+Kopi. Diakses tanggal: 15 Mei 2017.

Mujiburrahmad. 2011. Sistem Jaringan Pasok dan Nilai Tambah Ekonomi Kopi Organik (Studi Kasus di KBQ Baburrayan Kabupaten Aceh Tengah). Jurnal Agrisep. Vol. 12 No.1.

Ni Luh Made Indah Murdyani Dewi, I Wayan Budiasa, dan Ida Ayu Listia Dewi. 2015. Analisis Finansial dan Nilai Tambah Pengolahan Kopi Arabika di Koperasi Tani Manik Sedana Kabupaten Bangli. Jurnal agribisnis dan agrowisata Vol.4 No. 5.

Tambarta, Emmia. 2017. Analisis Nilai Tambah dan Strategi Pengembangan Olahan Kopi Arabika di Kabupaten Bener Meriah Aceh. Jurnal Institut Pertanian Bogor. 5 (515-519). 